\title{
Scalp Lesions Referred For Surgical Procedures: Single-Center 5-year Experience in Southwestern Poland
}

\author{
IWONA CHLEBICKA, ALEKSANDRA A. STEFANIAK, ANNA GAWDZIK, \\ ALICJA RYGAŁ, ŁUKASZ MATUSIAK and JACEK C. SZEPIETOWSKI \\ Department of Dermatology, Venereology and Allergology, Wroclaw Medical University, Wroctaw, Poland
}

\begin{abstract}
Background/Aim: The head is a body site with a particular predisposition to skin malignancies due to exposure to $U V$ radiation. The aim of the study was to better elucidate the characteristics of skin lesions that develop on the scalp. Patients and Methods: A retrospective review of all excised and histologically assessed lesions of the scalp at a single dermatosurgery unit throughout a fiveyear period was performed. Demographic features and lesion characteristics were compiled and analyzed. Results: Among 5,601 procedures during the analyzed period, 293 were performed on lesions on the scalp area $(5.2 \%)$ with a mean patient age of $66 \pm 19.7$ years. The defects were closed, mainly using primary closure, followed by skin grafts, and, least often, flaps $(65.1 \%, 28.5 \%, 4.9 \%$, respectively). Two thirds of the excised scalp lesions were histologically confirmed as malignant scalp tumors (mostly basal cell carcinomas followed by squamous cell carcinomas). Conclusion: The vast majority of scalp lesions referred for surgical procedures appeared to be malignant. Therefore, dermatologists should pay special attention to the scalp by examining it thoroughly, as the lesions may be hidden by hair.
\end{abstract}

The head is a body site with a particular predisposition to skin malignancies (1-3). This is due to its frequent exposure to ultraviolet radiation (UV). Tumors in the area of the scalp may be overlooked due to long hair or their occipital or postauricular location. Additionally, UV exposure of the

This article is freely accessible online.

Correspondence to: Prof. Dr. Jacek C. Szepietowski, Department of Dermatology, Venereology and Allergology, Wroclaw Medical University, Chałubińskiego 1, 50-368 Wrocław, Poland. Tel: +48 717842286, Fax: +48 713270942, e-mail: jacek.szepietowski@ umed.wroc.pl

Key Words: Basal cell carcinoma, dermatologic surgery, scalp lesions, squamous cell carcinoma. frontal area as well as other scalp areas in patients with androgenetic alopecia is very high $(1,3)$. This study aimed to provide the characteristics of a group of subjects treated at the Dermatosurgery Unit of the Department of Dermatology, Venereology and Allegrology of Wroclaw Medical University in Poland for scalp lesions with particular reference to age, sex, amount, location and surgical methods of treatment.

\section{Patients and Methods}

Patients. We performed a retrospective review of all excised and histologically assessed lesions of the scalp between January 2014 and June 2019. The population under study was treated at the Dermatosurgery Unit of the Department of Dermatology, Venereology and Allegrology of Wroclaw Medical University in Poland, which provides specialized surgical treatment of nonmelanoma skin cancers and other skin tumors/lesions to the estimated population in Southwestern Poland of 2,900,000 inhabitants (according to the 2019 census) (Figure 1).

All cases of scalp lesions treated surgically and histologically confirmed were included in the study. For this study, the scalp was defined as the area posterior to the hairline, including the forehead and temple, however not including the auricular areas. All subsequent patients regardless of age, immunosuppression, hereditary skin cancer or skin cancer combined with another malignancy were included in the study.

For each lesion, the following data were extracted via manual search of medical charts: age of patients at the time of treatment, location of each lesion on scalp, tumor size, postsurgical defect reconstruction method and histopathologic diagnosis. The final diagnosis was based on histopathological findings in all cases. The following locations of the scalp were considered: frontal, temporal, occipital, parietal and apex. The age of patients was divided in 5 categories: 5-18 years, 19-39 years, 40-59 years, 60-79 years, 7079 years and more than 80 years. Size of the lesions was divided into 5 categories (diameter): $<10 \mathrm{~mm}, 10-19 \mathrm{~mm}, 20-29 \mathrm{~mm}, 30-39$ $\mathrm{mm}, 40-49 \mathrm{~mm}$ and $>50 \mathrm{~mm}$.

Statistical analysis. Comparisons between groups were performed using the Pearson's Chi-squared test. The level of significance was set at $\alpha=0.05$. The resulting $p$-values were considered significant if $p<0.05$. Statistical analyses were performed using the Statistica 12 software (StatSoft, Tulsa, OK, USA). 


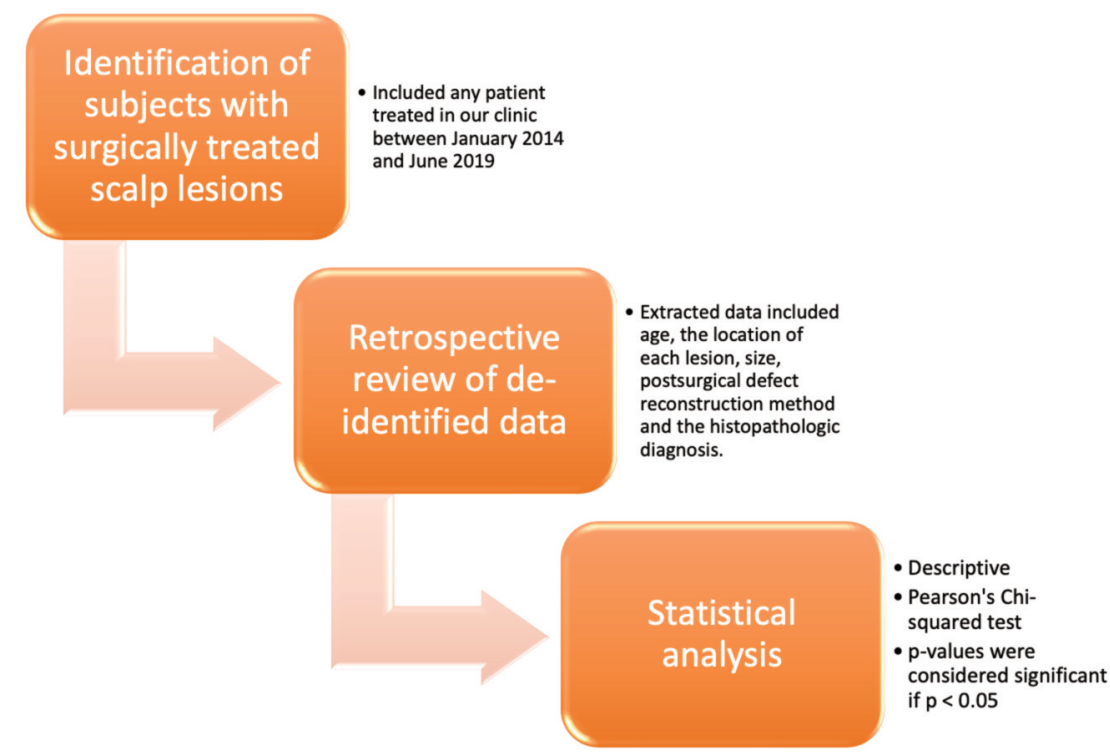

Figure 1. Flowchart of the study.

\section{Results}

Among the 5,601 procedures, 293 were performed on lesions on the scalp area (5.2\%). There were $169(58 \%)$ men and $124(42 \%)$ women (male:female ratio 1.36:1). The age range was from 5 to 96 years with a mean age of $66 \pm 19.7$ years. A group of $8(3 \%)$ patients was under 18 years of age. More than $70 \%$ of patients were aged 60 and older, with the highest proportion in the age of 60-79 years (39\%) (Table I).

Altogether, 309 lesions were excised. Sixteen patients had had more than 1 lesion of the scalp removed. The lesions occurred most commonly on the apex of the head, temporal surface and frontal region of the scalp. The anatomical distribution of scalp lesions is presented in Figure 2. Of the 309 lesions, only 105 were measured. Lesion size ranged from 5 to $80 \mathrm{~mm}$ in maximum diameter. Most lesions measured less than $10 \mathrm{~mm}(29.5 \%)$, followed by lesions with a diameter from 10 to $19 \mathrm{~mm}(26.7 \%)$ (Table I).

All lesions were excised with a 2-6 mm margin, according to general guidelines. The defects were closed, mainly using primary closure (PC) $-65 \%$, less often using full-thickness skin grafts (SG) $-28.5 \%$ and least often using flaps (local or regional) $-4.9 \%$ of all the procedures. Five defects smaller than $29 \mathrm{~mm}$ were left for self-healing (Table I). The method of reconstruction differed according to the size of the tumor. The bigger the size of the tumor, the more commonly advanced techniques for the closure were used, such as SG ( $p=0.00013$ ) (Figure 3). A total of $88.1 \%$ of small defects (less than $20 \mathrm{~mm}$ ) and $32.6 \%$ of bigger defects (more than $20 \mathrm{~mm}$ ) were reconstructed with PC. The size of the biggest lesion repaired with $\mathrm{PC}$ was $70 \times 70 \mathrm{~mm}$. The $\mathrm{SG}$ was the second most common procedure of reconstruction. Most procedures were performed on male patients $(67 \%)$ and the mean age of patients was $75.3 \pm 12.9$ years. More than half of local flaps $(53.3 \%)$ were performed on lesions in the forehead location. All flaps were performed on lesions sized between 10 and $39 \mathrm{~mm}$, with the majority in the size category 20-29 $\mathrm{mm}(57.1 \%)$.

More than half of the studied patients had histologically confirmed BCC (52.1\%), followed by SCC (11.3\%). Altogether, 196 non-melanoma skin carcinomas were excised. Among the benign lesions, the most common were melanocytic naevi (6.5\%) (Table II). Regarding the gender of patients, in men the most frequent lesions were BCC $(51.2 \%)$, followed by SCC (18.5\%), sebaceous naevi $(5.6 \%)$, and melanocytic naevi $(5.6 \%)$. In women, it was BCC $(64 \%)$, followed by melanocytic naevi $(9 \%)$ and SCC (4\%). This difference between men and women in the proportions of BCC and SCC was statistically significant $(p=0.0002)$. The ratio $\mathrm{BCC}$ to $\mathrm{SCC}$ was assessed as $3.7: 1$ in the whole studied population, 2.8:1 in men and 15.6:1 in women, respectively. Two thirds of the excessed scalp lesions were histologically confirmed malignant scalp tumors (BCC, SCC, dermatofibrosarcoma protuberans, atypical intradermal smooth muscle neoplasm).

\section{Discussion}

In recent years, the rising incidence rates of both melanoma and non-melanoma skin cancer worldwide, likely due to a combination of greater ultraviolet light exposure, changes in lifestyle, greater longevity, and ozone depletion (4), have 
Table I. General demographic and lesion characteristics of the 293 examined patients.

\begin{tabular}{lc}
\hline Characteristic & Value \\
\hline Number of patients & $293(169$ Males/124 Females) \\
Mean age of patients & $66 \pm 19.7(5-96)$ \\
at the time of treatment & \\
Age distribution (years) & \\
$5-18$ & 8 patients $(2.7 \%)$ \\
$19-39$ & 31 patients $(10.6 \%)$ \\
$40-59$ & 42 patients $(14.3 \%)$ \\
$60-79$ & 115 patients $(39.3 \%)$ \\
$80-96$ & 97 patients $(33.1 \%)$ \\
Mean number of scalp lesions & $1.04 /$ patient \\
Size diameter (mm) & \\
$<10$ & $31(10.1 \%)$ \\
$10-19$ & $28(9.1 \%)$ \\
$20-29$ & $27(8.7 \%)$ \\
$30-39$ & $10(3.2 \%)$ \\
$40-49$ & $4(1.3 \%)$ \\
$>50$ & $5(1.6 \%)$ \\
Lack of data & $204(66 \%)$ \\
Method of defect reconstruction & \\
Primary closure & $201(65 \%)$ \\
Graft & $88(28.5 \%)$ \\
Flap & $15(4.9 \%)$ \\
Local flap & 7 \\
V-Y local flap & 1 \\
H-flap & 1 \\
No data & 6 \\
Self-healing & $5(1.6 \%)$ \\
\hline &
\end{tabular}

increased the need for better knowledge of tumor features and improvement of available treatment effectiveness.

To the best of our knowledge, there is only one similar report (5) of scalp lesions available in the English language in the MEDLINE database. The comparison among similar series is summarized in Table III. A few reports consisted only of malignant tumors of the scalp (6-10) and one was performed on a pediatric population (11). In our study, we found that the majority of malignant scalp tumors occurred in middle-aged and elderly individuals, which is consistent with the previous reports (6-10). Overall, approximately $70 \%$ of all lesions treated in our Unit were malignant.

Turk et al. (5) reported a lower percentage of malignant lesions, most likely due to the different age group of the studied population (younger patients with a mean age of 44.3 years). Moreover, they collected patients from three Departments: Neurosurgery, Plastic Surgery and General Surgery. Most of the results $(58.6 \%)$ are from the General Surgery Department, which may also reflect on the differences in the results. Our cohort of patients demonstrated that BCC was the most common malignant scalp tumor, followed by SCC, as in other studies (6-10). The ratio between excised

\section{Scalp site}

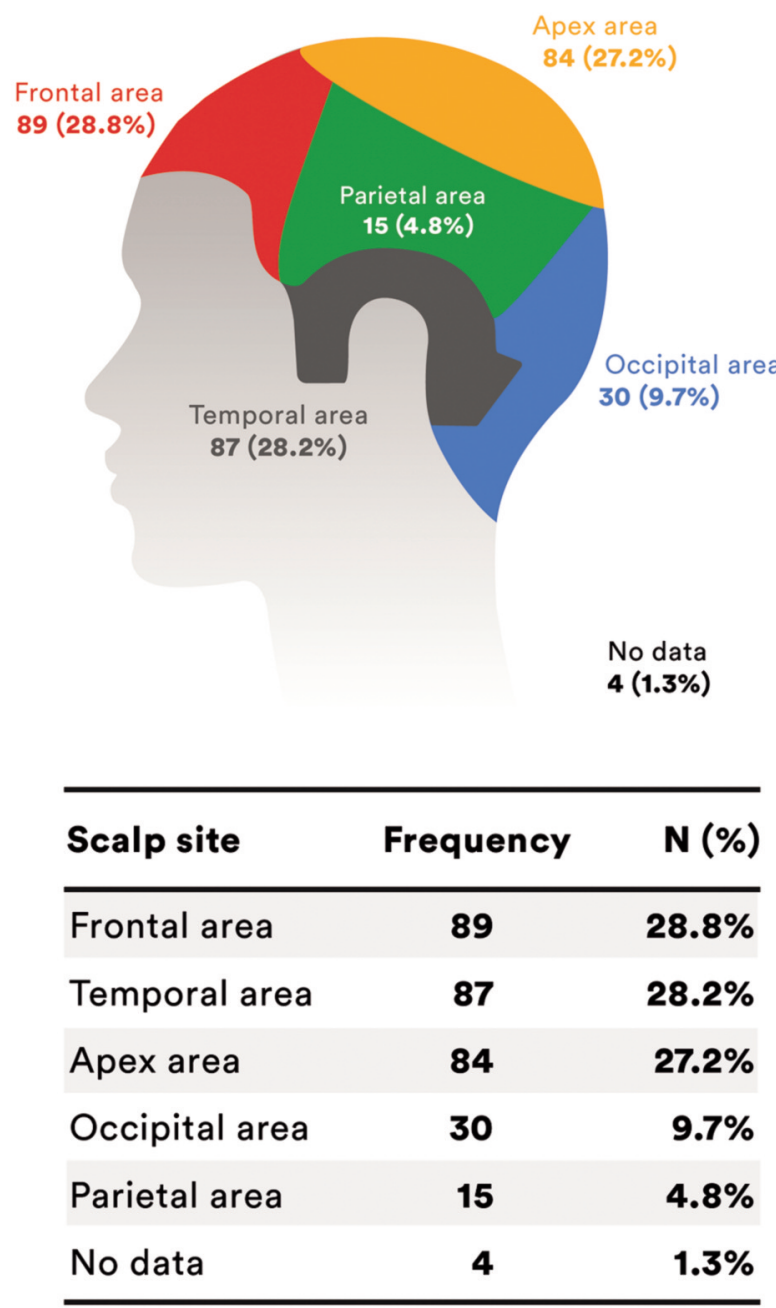

Figure 2. Anatomical distribution of the scalp lesions.

BCC and SCC was 3.74:1 in our whole studied population, and this is in accordance with other studies in high-incidence populations $(1,12,13)$. In populations at higher latitudes and lower risk, the occurrence of $\mathrm{BCC}$ can be up to fivefold higher than SCC $(3,14)$. Although it is generally accepted that BCC and SCC are the most frequent malignant non-melanoma scalp tumors, there is a difference in the incidence and tumor type preponderance concerning gender. We found that the ratio of BCC and SCC on the scalp was higher in men than in women, a pattern that has also been reported previously $(1-3,15)$. These findings in men and women are not fully elucidated and could stem from differences in the intensity of solar exposure (occupations that require outdoor activities, sunbathing habits, protective effects of creams). Moreover, there are numerous 


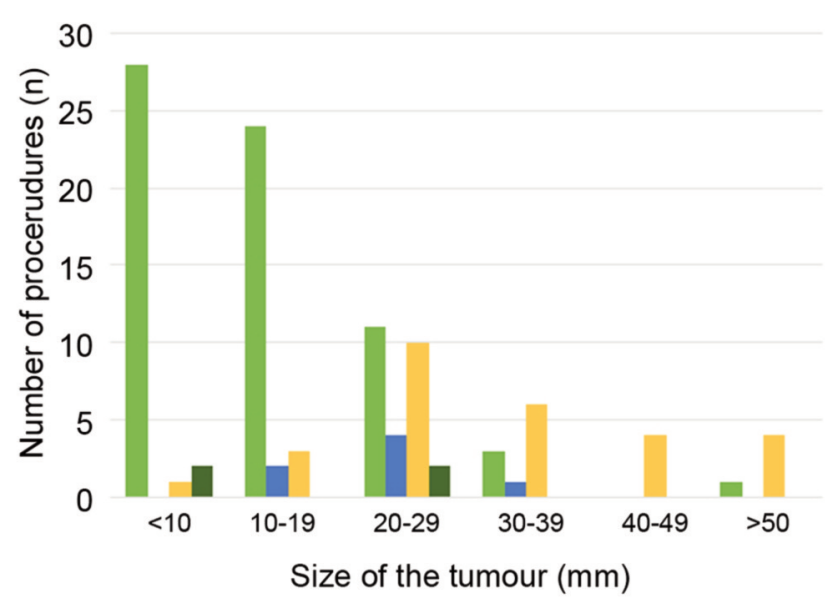

- Primary closure

- Flap

- Graft

- Self-healing

Figure 3. The postsurgical defect reconstruction technique used according to tumor size.
Table II. Histological diagnosis of the excised lesions.

\begin{tabular}{lc}
\hline Type of lesion & \\
\hline Malignant (66.7\%) & \\
BCC & $161(52.1 \%)$ \\
SCC & $35(11.3 \%)$ \\
Melanoma & $2(0.7 \%)$ \\
Dermatofibrosarcoma protuberans & $2(0.7 \%)$ \\
Atypical intradermal smooth muscle neoplasm & $1(0.3 \%)$ \\
Bowen's disease (SCC in situ) & $5(1.6 \%)$ \\
Benign (33.3\%) & \\
Melanocytic naevi & $20(6.5 \%)$ \\
Sebaceous naevi & $13(4.2 \%)$ \\
Seborrheic keratosis & $9(2.9 \%)$ \\
Cylindroma & $9(2.9 \%)$ \\
Atheroma & $8(2.6 \%)$ \\
Actinic keratosis & $7(2.3 \%)$ \\
Cutaneous horn & $5(1.6 \%)$ \\
Scar & $3(1 \%)$ \\
Folliculitis abscedens & $2(0.6 \%)$ \\
Keratoacanthoma & $1(0.3 \%)$ \\
Other (lipoma, neurofibroma, epidermal naevi, & \\
trichilemmal cyst, papilloma planoepitheliale & \\
hyperkeratoticum) & $26(8.4 \%)$ \\
\hline
\end{tabular}

BCC: Basal cell carcinoma, SCC: squamous cell carcinoma.

Table III. Comparison of scalp lesions among our series and the report of Turk et al. (5).

\begin{tabular}{|c|c|c|c|c|c|c|c|c|}
\hline \multirow[t]{2}{*}{ Authors } & \multirow[t]{2}{*}{ Patients/lesions } & \multirow{2}{*}{$\begin{array}{l}\text { Duration of } \\
\text { the study }\end{array}$} & \multicolumn{6}{|c|}{ Histological diagnosis } \\
\hline & & & $\mathrm{BCC}$ & SCC & $\begin{array}{l}\text { Skin appendage } \\
\text { tumors* }\end{array}$ & MM & $\begin{array}{l}\text { Metastatic } \\
\text { tumors }\end{array}$ & $\begin{array}{l}\text { Benign } \\
\text { lesions }\end{array}$ \\
\hline $\begin{array}{l}\text { Turk et al. (5) } \\
\text { (2015) }\end{array}$ & 345 (no. of patients) & 3 years & $2.9 \%$ & $1.7 \%$ & $1.2 \%$ & $0 \%$ & $0.3 \%$ & $92.8 \%$ \\
\hline $\begin{array}{l}\text { Current study } \\
\text { (2019) }\end{array}$ & $\begin{array}{c}293 \text { (no. of patients), } \\
309 \text { (no. of lesions) }\end{array}$ & 5 years & $52.1 \%$ & $\begin{array}{c}12.9 \% \\
(1.6 \% \text { in situ })\end{array}$ & $1 \%$ & $0.7 \%$ & $0 \%$ & $31.3 \%$ \\
\hline
\end{tabular}

BCC: Basal cell carcinoma, SCC: squamous cell carcinoma, MM: malignant melanoma. *Skin appendage tumors: eccrine cell carcinoma, merkel cell carcinoma, sebaceous carcinoma, dermatofibrosarcoma protuberans, atypical intradermal smooth muscle neoplasm.

examples of actinic keratoses and SCC seen in the scalp of men but not encountered in women, which may be due to the fact that women retain their hairline and that men lose hair earlier than women.

As for melanoma, Minor et al. (6) mentioned that melanoma was the third most common variety of scalp tumours. However, in our study, melanoma comprised only $0.7 \%$ of all excised lesions. In Poland, the majority of melanomas are treated in oncologic wards, and this could explain the observed differences. Dermatologists deal only with non-clear clinical presentations of melanomas, like those masquerading as other skin lesions (16) and/or clinically amelanotic melanomas.
Although the scalp is one of the most common sites of solid tumor metastasis $(4,17)$, in this study, there were no metastases found in the excised lesions. Metastases of the scalp are mostly a late sign of advanced internal malignancies. They may also be the first visible sign of malignancy (17-21). In the study conducted by Chiu et al . (7) metastases of the scalp skin were the third most common malignant lesions (after BCC and SCC) in this location.

The areas of the highest incidence of skin cancer of the scalp were the frontal regions, temporal area and the apex $(28.8 \%$, $28.2 \%, 27.2 \%$, respectively). These are the regions of the scalp most vulnerable to sun exposure in everyday situations. Moreover, the apex of the scalp has natural whorled patterns of 
hair, creating potential gaps that allow ultraviolet exposure of the scalp. In our study, in scalp areas most commonly covered with hair, such as occipital area and parietal areas, the incidence of lesions was very low (9.7\% and $4.6 \%$, respectively).

The growth pattern of scalp tumors is significantly affected by resistance to infiltration caused by the scalp's stratified structure. Given the site-specific, vertical limitation created by the cranial bones, tumors characteristically grow horizontally. Moreover, the skin of the scalp is usually very tense. All these features may cause difficulties in managing scalp lesions. Kumar and colleagues (22) stated that surgical resection using margins of $5 \mathrm{~mm}$ and defect closure using a flap, graft, or primary suture achieved a satisfactory tumor clearance rate in the head and neck of approximately $95 \%$ for SCCs and more than $96 \%$ for BCCs. Cosmetic issues might also of importance when dealing with scalp tumors.

PC, considered to be a technique with good aesthetic results, is predominantly used for small defects of up to 2$\mathrm{cm}^{2}$ area because of the scarcity of tissue in this area and the risk of increased tension on the wound edges may impair healing (23). In our study, $88.1 \%$ of small defects (smaller than $20 \mathrm{~mm}$ ) were closed with PC. However, if the symmetry of the face and natural appearance of the hairline and eyebrow line may be preserved, PC should also be considered, even for bigger defects (24). In the provided data, 32.7\% of larger defects (bigger than $20 \mathrm{~mm}$ ) were closed with PC as well.

Local advancement and rotation flaps, which are standard options for scalp reconstruction (23), result in good aesthetic outcomes and provide a reasonable supply of tissue to cover large defects. However, these techniques require for a long operation with a relatively high risk of complications (25, 26) in comparison with SG and PC. We used this technique mainly to repair mid-sized lesions (10-39 mm) located mostly on the forehead area to preserve the natural hairline and eyebrow line. In our Department, an SG is the preferred technique for achieving the 5-6 mm security margin of healthy tissues in elderly patients with more extensive lesions. The SG technique provides more options if secondary recurrences take place. Therefore, we suggest SG as the technique of defect closure of choice for patients of more advanced age and advanced hair loss.

BCCs, SCCs, and especially angiosarcoma and dermatofibrosarcoma protuberans can have aggressive and destructive behaviors, invade beyond the periosteum, skull bone, dura, and even brain, and result in profound morbidity and mortality (27-35). However, in our study, the tumors were limited only to the skin.

We are aware of the limitations of our study. It was retrospective, which prevented us from considering further parameters for analysis, such as the subtype of BCC, because of incomplete data. Additionally, the study was conducted in only one dermatological surgery center. Due to specific health care arrangements in our country - the vast majority of melanomas are treated in Oncology Departments - thus, the results may not be representative for other countries.

In conclusion, as patients themselves cannot thoroughly examine their own scalp, we suggest that physicians of any branch of medicine perform scalp inspections in general screening for skin cancers. On the whole, the vast majority of scalp lesions referred for surgical procedures appeared to be malignant. Therefore, dermatologists should pay special attention to the scalp by examining it thoroughly, as the lesions may be hidden by hair. A prospective study defining the prevalence of skin lesions on the scalp would be appreciated.

\section{Conflicts of Interest}

The Authors have no conflicts of interest to declare.

\section{Authors' Contributions}

All Authors made substantial contributions to the conception and design of this protocol. All Authors have critically read this manuscript and have made their revisions, and they have all approved this final version for submission. All Authors agree to be accountable for the future integrity of this study.

\section{References}

1 Youl PH, Janda M, Aitken JF, Del Mar CB, Whiteman DC and Baade PD: Body-site distribution of skin cancer, pre-malignant and common benign pigmented lesions excised in general practice. Br J Dermatol 165: 35-43, 2011. PMID: 21443534. DOI: $10.1111 / \mathrm{j} .1365-2133.2011 .10337 . x$

2 Subramaniam P, Olsen CM, Thompson BS, Whiteman DC and Neale RE: Anatomical distributions of basal cell carcinoma and squamous cell carcinoma in a population-based study in Queensland, Australia. JAMA Dermatol 153: 175-182, 2017. PMID: 27892984. DOI: 10.1001/jamadermatol.2016.4070

3 Franceschi S, Levi F, Randimbison L and La Vecchia C: Site distribution of different types of skin cancer: New aetiological clues. Int J Cancer 67: 24-28, 1996. PMID: 8690520. DOI: $10.1002 /($ S ICI ) 1097-0215(19960703)67:1<24::AIDIJC6>3.0.CO;2-1.

4 Böni R, Schuster C, Nehrhoff B and Burg G: Epidemiology of skin cancer. Neuroendocrinol Lett 23: 48-51, 2002. PMID: 12163848. DOI: 10.3109/9781420019964-9

5 Türk CÇ, Bacanlı A and Kara NN: Incidence and clinical significance of lesions presenting as a scalp mass in adult patients. Acta Neurochir (Wien) 157: 217-223, 2015. PMID: 25380646. DOI: 10.1007/s00701-014-2266-7

6 Minor LB and Panje WR: Malignant neoplasms of the scalp. Etiology, resection, and reconstruction. Otolaryngol Clin North Am 26: 279-293, 1993. PMID: 8460043.

7 Chiu CS, Lin CY, Kuo TT, Kuan YZ, Chen MJ, Ho HC, Yang LC, Chen $\mathrm{CH}$, Shih IH, Hong HS and Chuang YH: Malignant cutaneous tumors of the scalp: A study of demographic characteristics and histologic distributions of 398 Taiwanese patients. J Am Acad Dermatol 56: 448-452, 2007. PMID: 17141358. DOI: 10.1016/j.jaad.2006.08.060 
8 Fong PH, Lee ST and Lim Tan SK: Primary scalp cancer in Singapore. Ann Acad Med Singapore 15: 67-70, 1986. PMID: 3707037.

9 Katz TM, Silapunt S, Goldberg LH, Jih MH and Kimyai-Asadi A: Analysis of 197 female scalp tumors treated with Mohs micrographic surgery. J Am Acad Dermatol 52: 291-294, 2005. PMID: 15692476. DOI: 10.1016/j.jaad.2004.09.010

10 Castillo Guevara RM, Peniche Castellanos A, Fierro Arias L, Ponce Olivera RM and Mercadillo Pérez P: Frecuencia de tumores en la piel cabelluda en el servicio de DermatoOncología del Hospital General de México. Un análisis retrospectivo de los últimos 10 años. Dermatologia Rev Mex 54: 173-176, 2010.

11 Yang C-C, Chen Y-A, Tsai Y-L, Shih I-H and Chen W: Neoplastic skin lesions of the scalp in children: A retrospective study of 265 cases in Taiwan. Eur J Dermatol 24: 70-75, 2014. PMID: 24334149. DOI: 10.1684/ejd.2013.2216

12 Raasch B, Maclennan R, Wronski I and Robertson I: Body site specific incidence of basal and squamous cell carcinoma in an exposed population, Townsville, Australia. Mutat Res 422: 101-106, 1996. PMID: 9920433. DOI: 10.1016/s0027-5107(98)00194-8

13 Staples MP, Elwood M, Burton RC, Williams JL, Marks R and Giles GG: Non-melanoma skin cancer in Australia: The 2002 national survey and trends since 1985. Med J Aust 184: 6-10, 2006. PMID: 16398622. DOI: 10.5694/j.1326-5377.2006.tb00086.x

14 Holme SA, Malinovszky K and Roberts DL: Changing trends in non-melanoma skin cancer in South Wales, 1988-98. Br J Dermatol 143: 1224-1229, 2000. PMID: 11122025. DOI: 10.1046/j.1365-2133.2000.03892.x

15 Buettner PG and Raasch BA: Incidence rates of skin cancer in Townsville, Australia. Int J Cancer 78: 587-593, 1998. PMID: 9808527. DOI: 10.1002/(sici)1097-0215(19981123)78:5<587:: aid-ijc10>3.0.co;2-e

16 Stefaniak A, Chlebicka I, Krajewski P, Woźniak Z and Szepietowski J: Do not judge a book by its cover: masquerading as keratoacanthoma. Acta Derm Venereol 100: adv00074, 2020. PMID: 32057085. DOI: 10.2340/00015555-3423

17 Schulman JM, Pauli ML, Neuhaus IM, Sanchez Rodriguez R, Taravati K, Shin US, McCalmont TH and Rosenblum MD: The distribution of cutaneous metastases correlates with local immunologic milieu. J Am Acad Dermatol 74: 470-476, 2016. PMID: 26778012. DOI: 10.1016/j.jaad.2015.10.012

18 Song Z, Lin B, Shao L and Zhang Y: Cutaneous metastasis as a initial presentation in advanced non-small cell lung cancer and its poor survival prognosis. J Cancer Res Clin Oncol 138: 1613-1617, 2012. PMID: 22581263. DOI: 10.1007/s00432-012-1239-6

19 Gupta PP, Gupta K, Gulia J, Agarwal D and Mehta D: Scalp lesion: A presenting feature of squamous cell carcinoma of lung. J Cancer Res Ther 6: 370-373, 2016. PMID: 21119281. DOI: 10.4103/0973-1482.73364

20 Salemis NS, Veloudis G, Spiliopoulos K, Nakos G, Vrizidis N and Gourgiotis S: Scalp metastasis as the first sign of small-cell lung cancer: Management and literature review. Int Surg 99: 325-329, 2014. DOI: 10.9738/INTSURG-D-13-00070.1

21 Farley R, Manolidis S and Ratner D: Adenocarcinoma of the lung metastatic to the skull presenting as a scalp cyst. J Am Acad Dermatol 54: 916-917, 2006. PMID: 25058760. DOI: 10.1016/ j.jaad.2006.01.060

22 Kumar P, Watson S, Brain AN, Davenport PJ, McWilliam LJ, Banerjee SS and Bisset DL: Incomplete excision of basal cell carcinoma: A prospective multicentre audit. Br J Plast Surg 55: 616-622, 2002. PMID: 12550113. DOI: 10.1054/bjps.2002.3948

23 Leedy JE, Janis JE and Rohrich RJ: Reconstruction of acquired scalp defects: An algorithmic approach. Plast Reconstr Surg 116: 1114, 2005. PMID: 16163072. DOI: 10.1097/01.prs.00001 $79188.25019 .6 \mathrm{c}$

24 Chlebicka I, Rygał A, Stefaniak AA and Szepietowski JC: Basal cell carcinoma - primary closure of moderate defect of mid forehead. Dermatol Ther, 2020. PMID: 32185858. DOI: 10.1111/ dth. 13322

25 Wang HT, Erdmann D, Olbrich KC, Friedman AH, Levin LS and Zenn MR: Free flap reconstruction of the scalp and calvaria of major neurosurgical resections in cancer patients: Lessons learned closing large, difficult wounds of the dura and skull. Plast Reconstr Surg 119: 865-872, 2007. PMID: 17312489. DOI: 10.1097/01.prs.0000240830.19716.c2

26 García del Campo JA, García de Marcos JA, del Castillo Pardo de Vera JL and García de Marcos MJ: Local flap reconstruction of large scalp defects. Med Oral Patol Oral Cir Bucal 13: E666670, 2008. PMID: 18830178.

27 Rockley PF, Robinson JK, Magid M and Goldblatt D: Dermatofibrosarcoma protuberans of the scalp: a series of cases. J Am Acad Dermatol 21: 278-283, 1989. PMID: 2768577. DOI: 10.1016/s0190-9622(89)70173-0

28 Etlik Ö, Bay A, Izmirli M, Uğraș S, Yilmaz N and Turan A: Deep intracranial extension of squamous cell carcinoma of the scalp. Pediatr Blood Cancer 45: 994-996, 2005. PMID: 16127670. DOI: $10.1002 /$ pbc.20427

29 Kovarik CL, Stewart D and Barnard JJ: Lethal basal cell carcinoma secondary to cerebral invasion. J Am Acad Dermatol 52: 149-151, 2005. PMID: 15627099. DOI: 10.1016/j.jaad. 2004.08.014

30 Sakamoto T, Mineura K, Kikuchi K and Kowada M: Intracranial invasion of scalp carcinoma. Report of five cases. Acta Neurochir (Wien) 98: 66-69, 1989. PMID: 2741737. DOI: 10.1007/bf01407179

31 Mathieu D and Fortin D: Intracranial invasion of a basal cell carcinoma of the scalp. Can J Neurol Sci 32: 546-548, 2005. PMID: 16408590. DOI: 10.1017/s0317167100004595

32 Schroeder M, Kestlmeier R, Schlegel J and Trappe AE: Extensive cerebral invasion of a basal cell carcinoma of the scalp. Eur J Surg Oncol 27: 510-511, 2001. PMID: 11504526. DOI: $10.1053 /$ ejso.2000.1100

33 Stern HS and Haertsch P: Local recurrence and intracerebral spread of squamous cell carcinoma of the scalp. Plast Reconstr Surg 85: 284-288, 1990. PMID: 2300637. DOI: 10.1097/ 00006534-199002000-00021

34 Peters CR, Dinner MI, Dolsky RL, Bailin PL and Hardy RW: The combined multidisciplinary approach to invasive basal cell tumors of the scalp. Ann Plast Surg 4: 199-204, 1980. PMID: 7447270 .

35 Ellegala DB, Kligora C, Vandenberg S, Dumont A and Shaffrey ME: Intracranial metastasis of a primary scalp angiosarcoma: Case illustration. J Neurosurg 97: 725, 2002. DOI: 10.3171/jns. 2002.97.3.0725

Received April 2, 2020

Revised April 15, 2020

Accepted May 6, 2020 